\title{
Influence of the Nanoclay Concentration and Oil Viscosity on the Rheological and Tribological Properties of Nanoclay-Based Ecolubricants
}

\author{
Samuel D. Fernández-Silva ${ }^{1} \mathbb{D}$, Moisés García-Morales ${ }^{1} \mathbb{D}$, Charlène Ruffel $^{2}$ and Miguel A. Delgado ${ }^{1, *(\mathbb{D})}$ \\ 1 Centro de Investigación en Tecnología de Productos y Procesos Químicos (Pro2TecS), Departamento de \\ Ingeniería Química, Campus de "El Carmen", Universidad de Huelva, 21071 Huelva, Spain; \\ samuel.fernandez@diq.uhu.es (S.D.F.-S.); moises.garcia@diq.uhu.es (M.G.-M.) \\ 2 Ecole Nationale Supérieure des Industries Chimiques (ENSIC), Université de Lorraine, 54000 Nancy, France; \\ ruffel.charlene@gmail.com \\ * Correspondence: miguel.delgado@diq.uhu.es
}

check for updates

Citation: Fernández-Silva, S.D.; García-Morales, M.; Ruffel, C.; Delgado, M.A. Influence of the Nanoclay Concentration and Oil Viscosity on the Rheological and Tribological Properties of Nanoclay-Based Ecolubricants. Lubricants 2021, 9, 8. https:// doi.org/10.3390/lubricants9010008

Received: 6 November 2020

Accepted: 4 January 2021

Published: 8 January 2021

Publisher's Note: MDPI stays neutral with regard to jurisdictional clai$\mathrm{ms}$ in published maps and institutional affiliations.

Copyright: $\odot 2021$ by the authors. Licensee MDPI, Basel, Switzerland. This article is an open access article distributed under the terms and conditions of the Creative Commons Attribution (CC BY) license (https:// creativecommons.org/licenses/by/ $4.0 /)$.

\begin{abstract}
This manuscript describes a rheological and tribological study carried out on eco-friendly lubricants. These ecolubricants were made up of nanoclays as dispersed phase (a layered nanosilicate (montmorillonite Cloisite 15A) and a fiber-like nanoclay (sepiolite Pangel B20)) and vegetable-based oil as continuous phase (castor oil (CO), high oleic sunflower oil (HOSO) and their mixtures). A series of nanoclay-based ecolubricants were prepared by varying both nanoclay concentration and base oil, and thus, its viscosity. Friction and wear behaviors were assessed by using a ball-onthree plates tribometer cell. The results showed that the fiber-like sepiolite Pangel B20 yielded an important reduction in the wear scar diameter, thus revealing its potential as anti-wear and loadcarrying additive in ecolubricant formulations, while Cloisite 15A proved to have friction improving properties. These anti-wear and friction reducing properties were found to be influenced by both nanoclay concentration and oil viscosity.
\end{abstract}

Keywords: ecolubricants; friction coefficient; wear; nanoclays; sepiolite; castor oil

\section{Introduction}

Lubricants are extended and important industrial products composed of $70-93 \%$ base stocks (mineral, synthetic, or vegetable oil) and 7-30\% additives which are intended to improve some of the base oil's properties or add new properties [1]. Lubricants are used in a great deal of fields and types of machinery in order to reduce friction and wear, facilitate the dissipation of heat released in the contact surfaces, and protect mating surfaces from the surrounding environment (contaminants, humidity, etc.). The worldwide demand for lubricants is very high, around 45.4 million metric tons in 2019 , with annual growth of $2 \%$ since 2012 [2].

In the twentieth century, many improvements and developments took place in the lubricants field, such as improvements in the refining process of mineral oils, development of additives, and generation of synthetic lubricants, among others. However, the extended use of lubricants has provoked serious consequences to the environment because they pollute waterways, soils, and air [3]. In fact, half of the used lubricants are piled up in the environment [1]. Thus, the global concern over the environmental pollution issue has led to a growing interest in the use of renewable resources in the fields of lubricants. Moreover, stricter environmental regulations, such as the European standards Ecolabel, $\mathrm{REACH}$, etc., have emerged with the aim to promote production of more environmentally friendly lubricants. Even though the ecological lubricants market increases by $10 \%$ every year, it does still represent only $1 \%$ of the global lubricant market [1].

Most ecological lubricants are made from vegetable oils. The availability and relatively low cost of vegetable oils makes them one of the most essential sustainable resources for 
ecolubricants [4]. Apart from being biodegradable and nontoxic, vegetable oils have excellent lubricity, high viscosity index, high flash point, and very low volatility. Despite that, vegetable oils oxidize easily, have a limited range of viscosity, and poor properties at low temperatures [4,5]. Castor oil and high oleic sunflower oil are potentially applicable as lubricant base oils. Castor oil is a non-edible crop, showing good performance at low temperatures, low volatility, high kinematic viscosity, and excellent lubrication properties, thanks to Van der Waals interactions and hydrogen bonds among the ricinoleic fatty acid molecules [6,7]. Higholeic sunflower oil has low volatility and suitable thermal resistance at high temperatures in comparison with other vegetable oils, such as soybean, sunflower, rapeseed, etc. [8].

The use of nanoparticles in lubricants have been shown to result in great improvements. As Lee et al. and Ghaednia and Jackson pointed out, nanoparticles may play different roles on the lubrication process. Thus, they can produce a protective film in contact surfaces and have rolling, mending, and polishing effects $[9,10]$. Many studies have highlighted their capacity to reduce friction and their anti-wear properties, with demonstrated friction reduction of around 70\% and wear volume reduction up to $75 \%$ [11]. Several kinds of nanoparticles were added to lubricants to improve their extreme pressure, anti-wear, and friction properties, to name a few. Prominent among these have been the friction reduction and anti-wear properties of metals, such as $\mathrm{Fe}, \mathrm{Cu}$, and $\mathrm{Co}[12,13]$, and metallic oxide nanoparticles, such as $\mathrm{CuO}, \mathrm{ZnO}, \mathrm{TiO}_{2}, \mathrm{SiO}_{2}$, or $\mathrm{Al}_{2} \mathrm{O}_{3}$ [14-17]. In addition, the anti-wear, antifriction, and load carrying properties of castor oil were significantly improved with the addition of hybrid nano oxides like $\mathrm{CeO}_{2}$ and polytetrafluoroethylene nanoparticles [18-20]. Li et al. demonstrated that small quantities of graphene additives could diminish friction and wear scars in steel/steel metal contacts [21]. Zhao et al. combined the best of both, nanographene sheets and a metal oxide, to reduce friction and wear [22]. Nanoclays have recently received much attention due not only to their capacity to reduce friction and wear, but also to their wide range of shapes and sizes [23]. With that said, Chizhik et al. and Singh \& Bhowmick, who performed different studies with nanoclays, such as bentonite and muscovite, observed a significant decrease in both friction and wear [24,25]. However, all these nanoparticles may have competitive effects [10]. On the one hand, they can reduce contact area which leads to a reduction of wear; on the other hand, they may generate friction due to their own contact with surfaces [10]. Moreover, the effects provoked by nanoparticles depend, among other factors, on their concentration, size distribution, size, shape, and hardness [3], and also on the environment, that is, the lubricant to which they are applied, and the load [10].

A great variety of nanoclays can be found as commercial materials. Phyllosilicates (layered nanosilicates) are the main category and include, among many others, montmorillonite, bentonite, and halloysite clay minerals. In contrast, sepiolites, showing fiber-like structures, are not really layered nanosilicates since their blocks are not sheets but ribbons forming an open channel similar to that of zeolites [26].

This study looks into the effects provoked by the addition of two types of nanoclays, a layered nanosilicate (Closite 15A) and a fiber-like sepiolite (Pangel B20), on the rheological and tribological properties of vegetable-based ecolubricants. Friction reduction properties and anti-wear effect of these nanoparticles were analyzed according to a central composite rotatable experimental design, based on both nanoclay concentrations and oil viscosity. The study has demonstrated the positive effect of these nanoclays on reducing friction and wear under certain lubrication conditions.

\section{Materials and Methods}

\subsection{Materials}

The commercial nanoclays, Cloisite 15A and Pangel B20, were selected for this study. Cloisite 15A is an organically modified nanoclay, in which the sodium ions (in the interlayer gallery) are replaced with quaternary ammonium salt ions in order to improve its dispersibility in organophilic media. The organic part of the modifier was 2Me2HT (Me: methyl and HT: hydrogenated tallow ( $\approx 65 \mathrm{wt} . \% \mathrm{c} 18 ; \approx 30 \mathrm{wt} . \% \mathrm{c} 16 ; \approx 5 \mathrm{wt} . \% \mathrm{c} 14))$. It is 
a layered montmorillonite with an interlayer distance of $31.5 \AA$, formed by two tetrahedral sheets of silicon and oxygen, and one octahedral sheet of silicon and aluminum in between [27]. Cloisite 15 A was supplied by Southern Clay Products (USA). Pangel B20 is a natural fiber-like sepiolite. Every fiber unit is composed of a sandwich-like structure of 2:1 tetrahedral sheets of silicon and oxygen (silica) and an interlayered octahedral sheet of magnesium oxide hydroxide. Oxygen atoms in the octahedral sheets are coordinated with magnesium cations and water to form ribbons. These units bundle to form a fiber-like structure with open channels of $3.7 \AA \times 10.6 \AA$. Due to the open structure, $\mathrm{Si}$-OH groups remain in the borders of the silica, thus coordinating with water groups $[26,28,29]$. Pangel B20 was provided by Tolsa (Madrid, Spain).

Castor oil (CO), with dynamic viscosity at $25{ }^{\circ} \mathrm{C}$ of $0.59 \mathrm{~Pa} \cdot \mathrm{s}$, was purchased from Guinama (Spain); and high oleic sunflower oil (HOSO) with $85 \mathrm{wt} . \%$ oleic acid and dynamic viscosity at $25^{\circ} \mathrm{C}$ of $0.068 \mathrm{~Pa} \cdot \mathrm{s}$, was kindly donated by "Instituto de la Grasa”, CSIC (Spain). The respective viscosities of the oils were $242.5 \mathrm{cSt}$ for $\mathrm{CO}$ and $38.5 \mathrm{cSt}$ for $\mathrm{HOSO}$ at $40^{\circ} \mathrm{C}$. Basic properties and compositional details of castor oil and $\mathrm{HOSO}$ can be found elsewhere [6,7].

\subsection{Experimental Design for the Nanoclay-Based Ecolubricants Formulation}

The formulations of the ecolubricants used in this study were carried out according to a central composite rotatable experimental design (also called Box-Wilson design), with two factors at five levels based on the response surface methodology (RSM), where the value of $\alpha$ was \pm 1.414 [30]. Ten dispersions were prepared, with nanoclays concentrations ranging from 0.5 to $6 \mathrm{wt} . \%$ and dispersing medium kinematic viscosities ranging from 38.5 to $242.5 \mathrm{cSt}$ at $40^{\circ} \mathrm{C}$, by preparing mixtures of both base oils, $\mathrm{CO}$ and HOSO. These mixtures were prepared according to the mixing rule described in Quinchia et al. [7]. Figure 1 shows the normalized values of both independent variables.

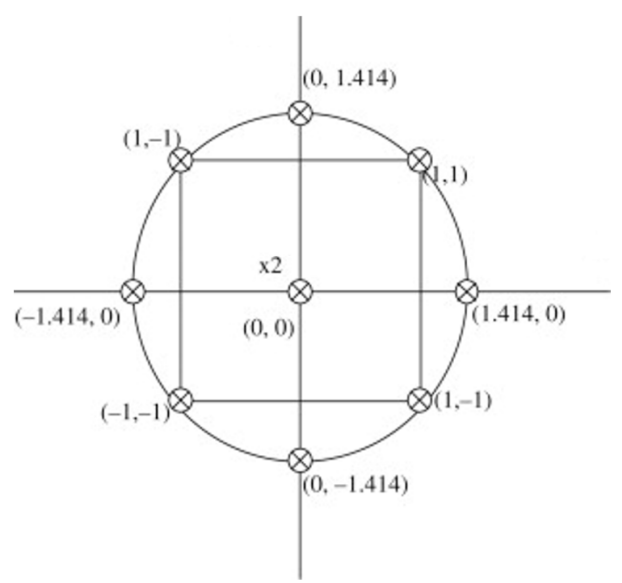

\begin{tabular}{|l|c|c|c|c|c|}
\hline Normalized values & -1.414 & -1 & 0 & +1 & +1.414 \\
\hline x (nanoclay concentration, wt. $\%)$ & 0.5 & 1.3 & 3.3 & 5.2 & 6.0 \\
\hline y (oil viscosity, cSt) & 38.5 & 68.4 & 140.5 & 212.6 & 242.5 \\
\hline
\end{tabular}

Figure 1. Central composite design with two variables (nanoclay concentration and oil viscosity) and the correspondence between experimental and normalized values of the variables studied (response surface methodology (RSM) analysis).

\subsection{Nanoclay-Based Ecolubricants Preparation}

"As-received" nanoclays were used in the preparation of the dispersions studied, according to a two-step protocol as reported by Maheswaran and Sunil [31]. The corresponding amount of nanoclay was dispersed in around $30 \mathrm{~g}$ of oil by using a small magnetic stirrer at $45{ }^{\circ} \mathrm{C}$ for $45 \mathrm{~min}$. Afterwards, the samples were sonicated for $45 \mathrm{~min}$ in a Power Sonic 405 sonication bath at its maximum power, taking care not to surpass $50{ }^{\circ} \mathrm{C}$. Finally, 
samples were cooled down to room temperature. In all cases, visual inspection allowed the conclusion that the dispersion quality was very good.

\subsection{Nanoclay-Based Ecolubricants Characterization}

The viscous flow behavior of the nanoclay-based ecolubricants was performed in a Physica MCR 301 (Anton Paar, Ostfildern-Scharnhausen, Germany) rheometer at $25{ }^{\circ} \mathrm{C}$, using a serrated plate-plate geometry ( $25 \mathrm{~mm}$ diameter, $1 \mathrm{~mm}$ gap) in order to avoid the so-called "wall-slip" phenomenon. The dynamic viscosity of these dispersions was measured within a shear rate range of $0.01-100 \mathrm{~s}^{-1}$. At least two replicates of each test were done on fresh samples.

A Physica MCR 501 rheometer coupled to a ball-on-three plates tribology cell was used in order to determine the friction coefficient, defined as the ratio between the friction force measured by the rotational rheometer and the applied normal force. This tribological device was composed of a lower part with three $45^{\circ}$ pitched steel plates (C45E-1.1191, hardness 25-30 HRC) and an upper part which sustains a fixed $12.7 \mathrm{~mm} \mathrm{100Cr6} \mathrm{bearing}$ ball [32]. The ball bearing was fixed in order to avoid rolling, thus allowing the tests to be performed under pure sliding friction conditions. The evolution of the friction coefficient was monitored every $3 \mathrm{~s}$ under a rotational speed sweep (1-500 rpm) at 10-40 N normal force (0.81-1.29 GPa Hertzian pressure), for $300 \mathrm{~s}$ and at room temperature. At least four replicates were carried out on fresh samples, and data shown have statistically significant values. Each test was run on new plates and ball bearings.

Wear was evaluated at a normal load of $40 \mathrm{~N}$ and a constant rotational speed of $40 \mathrm{rpm}$ (sliding velocity of $16 \mathrm{~mm} / \mathrm{s}$ ) for $1800 \mathrm{~s}$ at room temperature. The friction coefficient was registered every $9 \mathrm{~s}$. At least three replicates were carried out on fresh samples, and data shown have statistically significant values. All steel plates were properly cleaned with ethanol and dried at ambient conditions before performing the test. Both morphology and diameter of wear scars in the plates were examined by using an optical microscope, model Olympus BX52 (Tokyo, Japan), equipped with an Olympus C5050Z camera (Tokyo, Japan) and an objective of $4 x$. All optical measurements were carried out in duplicate.

\section{Results and Discussion}

\subsection{Viscous Flow Behaviour of Nanoclay-Based Ecolubricants}

Steady-state viscous flow tests revealed that most of the nanoclay-based dispersions studied behaved as shear-thinning fluids, i.e., viscosity decreases with increasing shear rate. Only the samples prepared with the organically modified nanoclay (Cloisite 15A) at concentrations equal to or lower than $1.3 \mathrm{wt} \%$, specifically the $(-1,+1),(-1.414,0)$, and $(-1,-1)$ samples, maintained their Newtonian behavior within the entire shear rate range studied, no matter the oil viscosity used. Conversely, Cloisite 15A concentrations equal to or higher than $3.3 \mathrm{wt}$.\% always turned the Newtonian viscous flow behavior of the vegetable oils studied, both pure and their mixtures, into Non-Newtonian. In the case of Pangel B20, all the formulations studied presented a shear-thinning behavior.

The pseudoplastic character shown by the Pangel B20-based dispersions was more remarkable than that for Cloisite 15A and deviated noticeably from the Newtonian behavior. As it was previously pointed out by Martín-Alfonso et al., the values of the flow index of gel-like dispersions based on sepiolite and castor oil were quite close to zero [33]. This is a typical viscous flow behavior that characterizes fiber-like nanoclays due to their capacity to form percolated networks, as reported in Kuznetsov et al. [34]. In fact, all samples prepared with the natural fiber-like sepiolite (Pangel B20) within the whole concentration range studied behaved as semisolid fluids at very low shear rates, similar to the yielding flow behavior observed for traditional lubricating greases [35], showing a shear-thinning response in the low and moderate shear rate region. In the high shear rate region, a tendency to reach a limiting viscosity was observed. At low shear rates, the nanoparticles form structures that offer resistance to flow. Thus, the dispersions viscosity is greatly affected by the nanoclay concentration [28,33]. Superior thickening properties may be 
attributed to Pangel B20 due to the structural skeleton and entanglements formed by the sepiolite fibers [36]. At high shear rates, the nanoparticles tend to line up in the flow direction and the nanoclays behave as noninteracting dispersed medium into the vegetable oil [37]. Thus, the viscous flow behavior of the pseudoplastic dispersions were fairly well fitted by the Sisko model (Equation (1)) with $\mathrm{R}^{2}$ values above 0.99 :

$$
\eta=\mu_{\infty}+\mathrm{K} \cdot \dot{\gamma}^{n-1}
$$

with $\mu_{\infty}$ being the high shear rate limiting viscosity $(\mathrm{Pa} \cdot \mathrm{s}), \mathrm{K}$ being the consistency index $\left(\mathrm{Pa} \cdot \mathrm{s}^{\mathrm{n}}\right)$, and $\mathrm{n}$ being the flow index. Values of these parameters can be seen in Table 1 . For the sake of including the three above formulations showing Newtonian behavior into the experimental design, a value of 1 was assigned ton, while $\mathrm{K}$ is, in actuality, the Newtonian viscosity (it does not exist as $\mu_{\infty}$ ).

Table 1. Rheological behavior at $25^{\circ} \mathrm{C}$ for the Cloisite 15A and Pangel B20-based dispersions studied, and their Sisko model fitting parameter values.

\begin{tabular}{|c|c|c|c|c|c|c|c|c|c|c|}
\hline \multirow{2}{*}{ Sample } & \multirow{2}{*}{$\begin{array}{c}\text { Nanoclay } \\
\text { Concentration } \\
\text { (wt. \%) }\end{array}$} & \multirow{2}{*}{$\begin{array}{c}\text { Base Oil } \\
\text { Viscosity (cSt) }\end{array}$} & \multicolumn{4}{|c|}{ Cloisite 15A } & \multicolumn{4}{|c|}{ Pangel B20 } \\
\hline & & & RB * & $\begin{array}{c}\mathrm{K} \\
\left(\mathrm{Pa} \cdot \mathrm{s}^{\mathrm{n}}\right)\end{array}$ & $n$ & $\begin{array}{c}\mu_{\infty} \\
(\mathbf{P a} \cdot \mathbf{s})\end{array}$ & $\mathbf{R B}$ * & $\begin{array}{c}\mathrm{K} \\
\left(\mathrm{Pa} \cdot \mathrm{s}^{\mathrm{n}}\right)\end{array}$ & $n$ & $\begin{array}{c}\mu_{\infty} \\
\mathbf{( P a} \cdot \mathbf{s})\end{array}$ \\
\hline $0,0 \mathrm{~A}$ & 3.3 & 140.5 & $\mathrm{P}$ & 1.287 & 0.428 & 0.346 & $\mathrm{P}$ & 33.572 & 0.111 & 0.529 \\
\hline $0,0 \mathrm{~B}$ & 3.3 & 140.5 & $\mathrm{P}$ & 1.215 & 0.516 & 0.299 & $\mathrm{P}$ & 29.523 & 0.095 & 0.650 \\
\hline$+1.414,0$ & 6.0 & 140.5 & $\mathrm{P}$ & 9.548 & 0.115 & 0.559 & $\mathrm{P}$ & 88.232 & 0.124 & 0.224 \\
\hline$-1.414,0$ & 0.5 & 140.5 & $\mathrm{~N}$ & 0.314 & 1 & - & $\mathrm{P}$ & 0.171 & 0.560 & 0.280 \\
\hline $0,+1.414$ & 3.3 & 242.5 & $\mathrm{P}$ & 0.756 & 0.727 & 0.656 & $\mathrm{P}$ & 31.252 & 0.136 & 0.772 \\
\hline $0,-1.414$ & 3.3 & 38.5 & $\mathrm{P}$ & 1.361 & 0.206 & 0.106 & $\mathrm{P}$ & 28.246 & 0.054 & 0.126 \\
\hline$+1,+1$ & 5.2 & 212.6 & $\mathrm{P}$ & 2.049 & 0.418 & 0.745 & $\mathrm{P}$ & 63.299 & 0.124 & 0.853 \\
\hline$+1,-1$ & 5.2 & 68.4 & $\mathrm{P}$ & 4.187 & 0.166 & 0.217 & $\mathrm{P}$ & 47.638 & 0.056 & 0.295 \\
\hline$-1,+1$ & 1.3 & 212.6 & $\mathrm{~N}$ & 0.638 & 1 & - & $\mathrm{P}$ & 1.976 & 0.212 & 0.602 \\
\hline$-1,-1$ & 1.3 & 68.4 & $\mathrm{~N}$ & 0.186 & 1 & - & $\mathrm{P}$ & 2.834 & 0.222 & 0.146 \\
\hline
\end{tabular}

* RB: Rheological behavior; P: Pseudoplastic; N: Newtonian.

As Delgado et al. reported, the values of the flow index, $n$, provide information about the viscous flow behavior dependence on shear, due to the induced orientation of the nanoclays particles in the continuous medium [38]. In this sense, it is noteworthy that all Pangel B20-based dispersions showed very low flow index (n) values, which is an unequivocal sign of their shear-thinning behavior. Figure 2 shows the response surface of the flow index and the statistical model obtained from multiple regression, as a function of nanoclay concentration and oil viscosity. As can be observed, the response surface methodology has revealed that the flow index of the Cloisite 15A-based dispersions presents an indirect dependence on nanoclay concentration and a direct dependence on oil viscosity. In contrast, the oil viscosity did not have any effect on the flow index of the Pangel B20-based samples. In this sense, it is noteworthy that such an effect could have been hampered by the structural skeleton formed by the fiber-like sepiolites as compared to the layered nanosilicates (Cloisite 15A). In fact, the Pangel B20 enhanced capacity to form percolated networks, involving both lower flow index values and their higher dependence on nanoclay concentration. In addition, the steric interactions among fiber-like sepiolite nanoparticles led, as compared to Cloisite 15A-based dispersions, to much higher viscosities within the shear rate studied.

The consistency index, which is the value of the dynamic viscosity at a shear rate of $1 \mathrm{~s}^{-1}$, only depends directly on nanoclay concentration for both nanoclays (Figure 3 ). These results are in agreement with other semi-solid lubricants, such as those previously reported for lithium lubricating greases by Delgado et al. [38]. Moreover, the stronger physical entanglements among Pangel B20 nanofibers yielded much higher values of consistency index (Table 1), up to 25 times higher than those obtained with Cloisite 15A. 


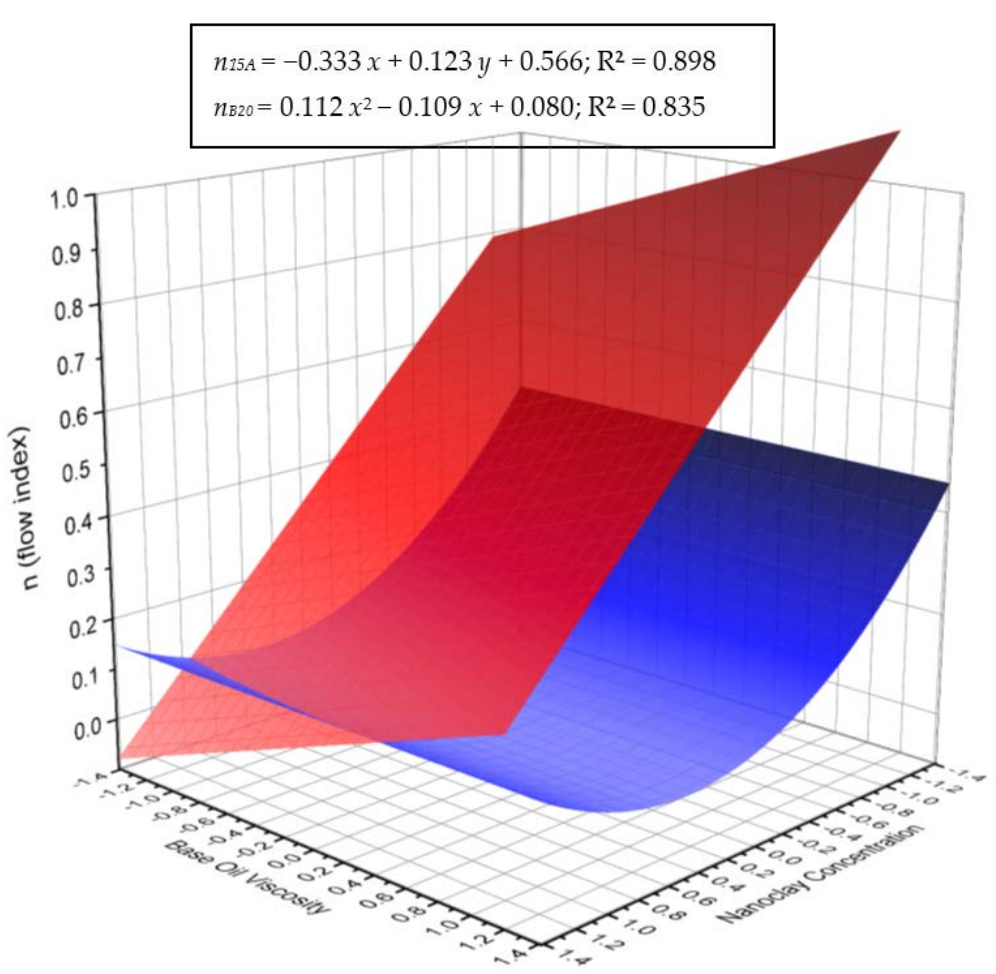

Figure 2. Response surface of the flow index (n) for Cloisite 15A (red) and Pangel B20 (blue) based dispersions as a function of normalized nanoclay concentration $(\mathrm{x})$ and base oil viscosity $(\mathrm{y})$.

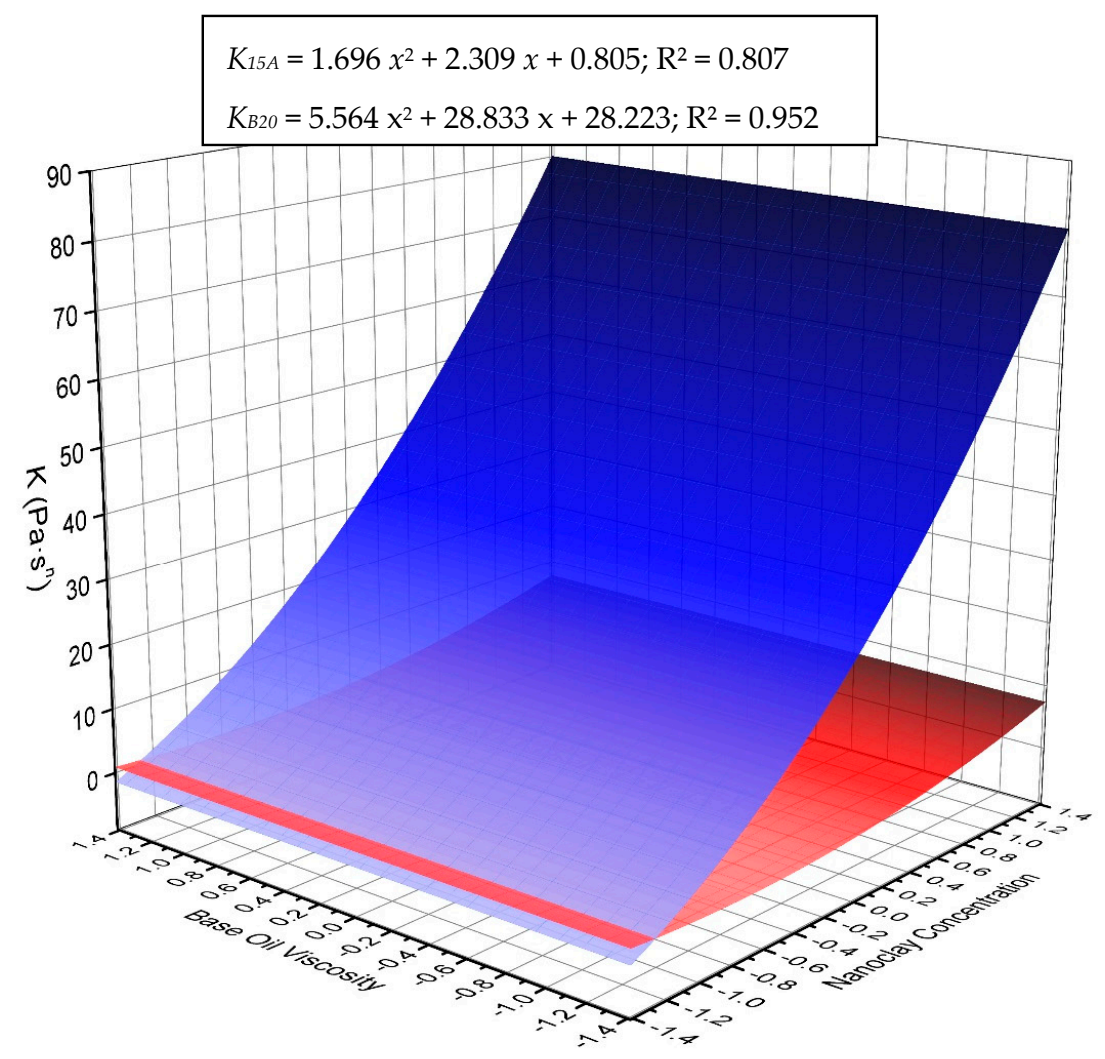

Figure 3. Response surface of the consistency index (K) for Closite 15A (red) and Pangel B20 (blue) based dispersions as a function of normalized nanoclay concentration $(x)$ and base oil viscosity $(y)$. 
Finally, special attention was paid to the high shear rate-limiting viscosity. As Delgado et al. highlighted, the values of some rheological parameters extrapolated at high shear rates could be used to link rheological and tribological parameters, such as the friction coefficient under mixed lubrication conditions [39]. Thus, Figure 4 shows the linear statistical models obtained from multiple regression and their corresponding response surface for the dynamic viscosity at $100 \mathrm{~s}^{-1}$ (representative of the high shear rate-limiting viscosity) as a function of both nanoclay concentration and base oil viscosity. For both variables, a direct relationship was found. The major contribution of concentration on the dynamic viscosity at $100 \mathrm{~s}^{-1}$ of Pangel B20 was noteworthy. On the contrary, the oil viscosity is the variable which mainly affects the high shear rate-limiting viscosity in the case of Cloisite 15A. Despite the microstructure collapse, which is expected at a high shear rate $[38,39]$, the Pangel B20 sepiolite may have retained a part of the physical interactions among its fibers, thereby enhancing the high shear rate-limiting viscosity in comparison with the layered montmorillonite (Cloisite 15A). In consequence, the Cloisite 15A nanoclay yielded a lower dependence of the high shear rate-limiting viscosity on concentration, as corroborated by a lower value of the coefficient associated to the x-variable in the linear regression model (0.126) as compared to Pangel B20 (0.532).

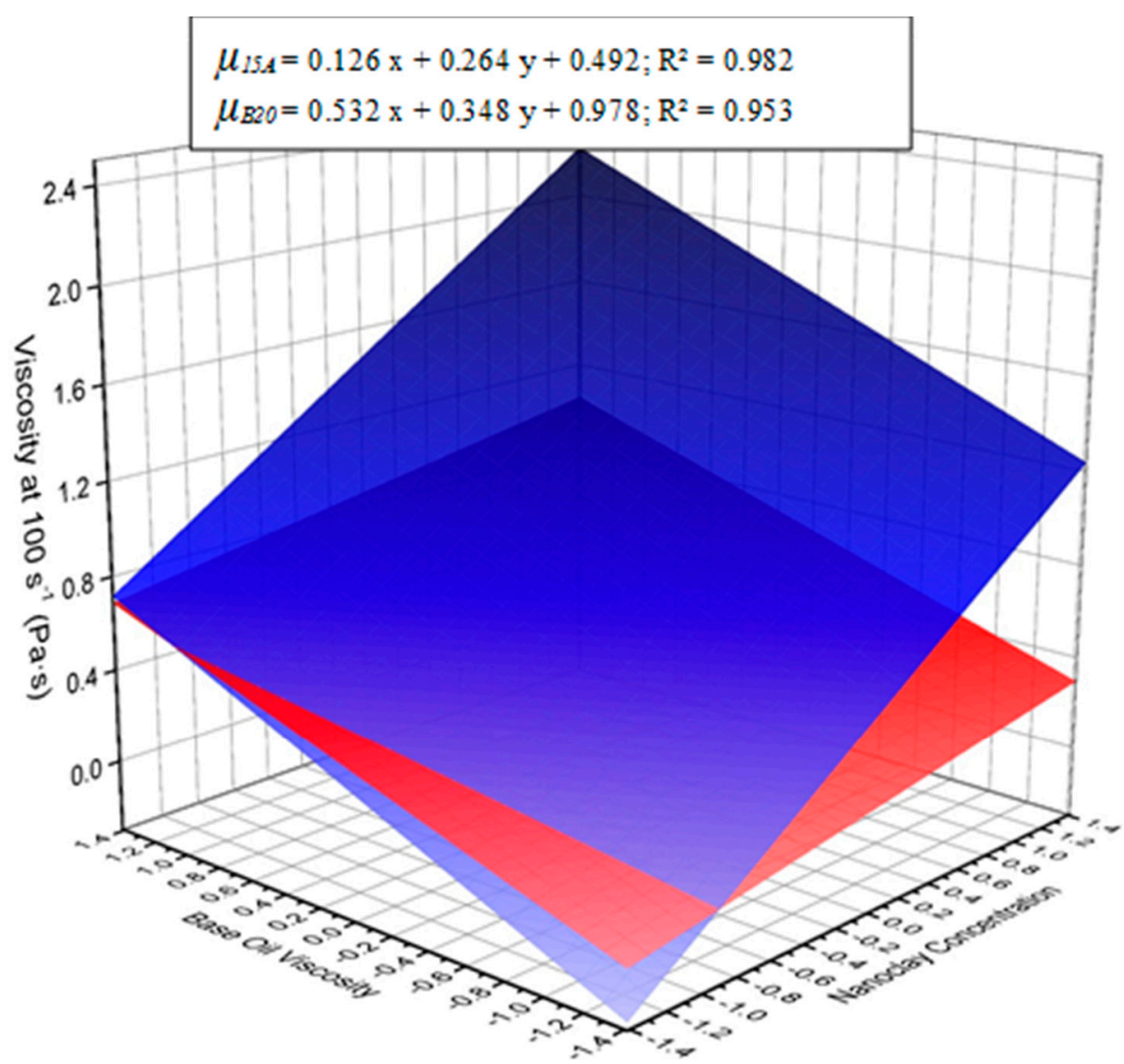

Figure 4. Response surface of the dynamic viscosity at $100 \mathrm{~s}^{-1}$ for Closite 15 A (red) Pangel B20 (blue) based dispersions as a function of the normalized nanoclay concentration (x) and base oil viscosity (y).

\subsection{Friction Analysis of Nanoclay-Based Ecolubricants}

In this section, the lubrication performance of the nanoclay-based ecolubricants studied were analyzed. Figures 5 and 6 depict, for Pangel B20 and Closite 15A, respectively, the variation of the friction coefficient with the Stribeck parameter $\left(S=u \cdot \mu_{\infty} / F_{N}\right.$, where $u$ is the sliding velocity $(\mathrm{mm} / \mathrm{s}) ; \mu_{\infty}$ is the high shear rate-limiting viscosity from the Sisko model (Pa.s); and $\mathrm{F}_{\mathrm{N}}$ is the axial force $(\mathrm{N})$ ) as a function of both nanoclay concentration and oil viscosity. The friction analysis was done under axial forces of 10 and $40 \mathrm{~N}$, which 
mean Hertzian pressures on each plate of 0.57 and $0.91 \mathrm{GPa}$, respectively, within a wide range of sliding velocity. According to Gonçalves et al. [40], the dimensionless Stribeck parameter, S, "normalizes" the abscissa of the curves, thus enabling direct comparison of the coefficients of friction of different lubricants when tested with the same surface's geometry, roughness, and material, while taking into account the operating conditions $\left(\mathrm{u} ; \mathrm{F}_{\mathrm{N}}\right)$ and the nanoclay-based lubricant properties at the average operating temperature of the test. In general, the evolution of the friction coefficient with the $S$ parameter fitted a Stribeck-like curve, with a well-defined transition from a boundary to hydrodynamic lubrication regime. Significant differences between the friction curves were appreciated, both throughout the sliding velocity range tested and at the two normal loads applied.

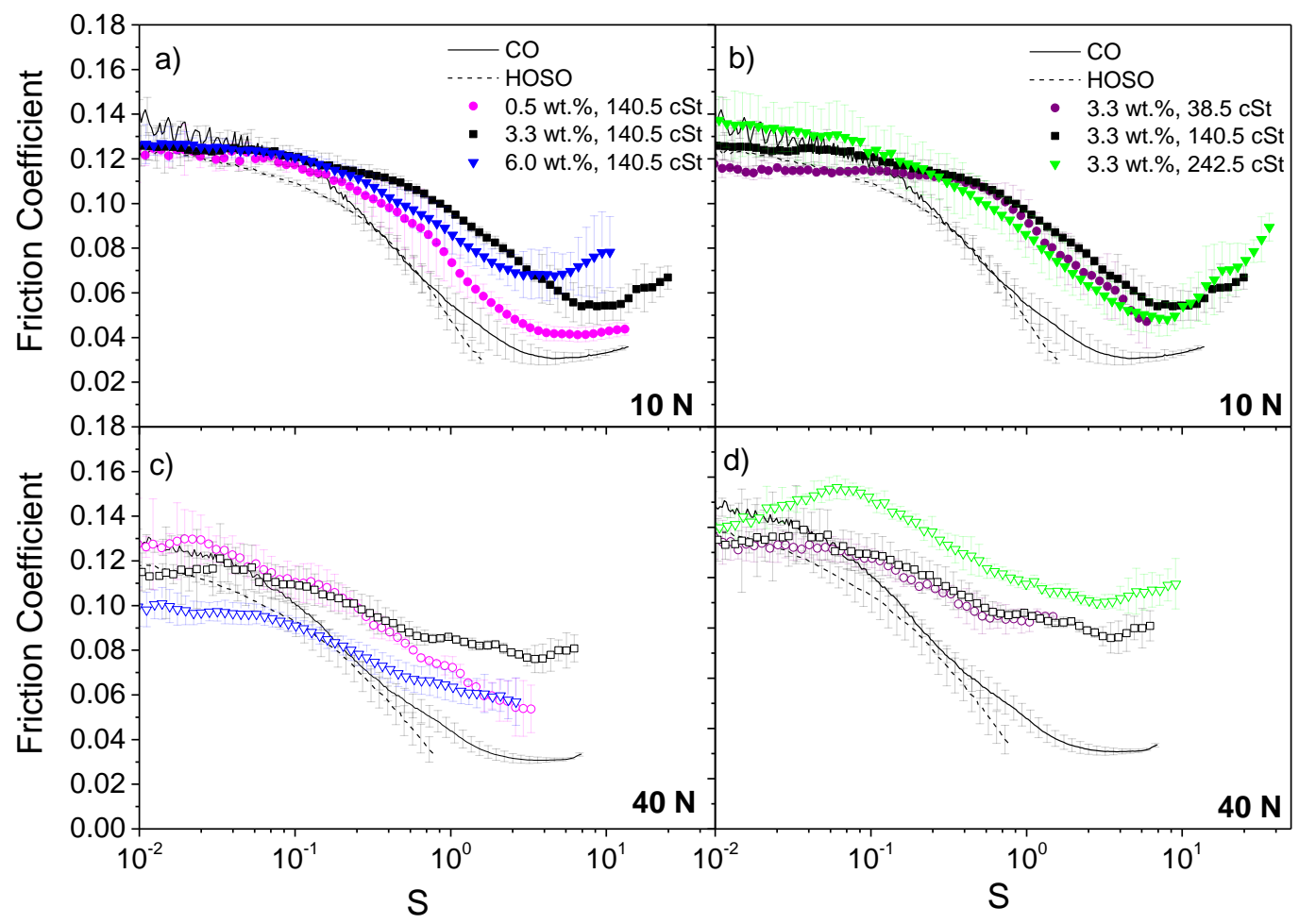

Figure 5. Evolution of the friction coefficient with the sliding velocity for Pangel B20-based dispersions at $25^{\circ} \mathrm{C}$ as a function of nanoclay concentration $(\mathbf{a}, \mathbf{c})$ and oil viscosity $(\mathbf{b}, \mathbf{d})$, at $10 \mathrm{~N}((\mathbf{a}, \mathbf{b})$ solid symbols) and $40 \mathrm{~N}((\mathbf{c}, \mathbf{d})$ empty symbols). Both neat vegetable oils curves were introduced as reference.

Figures $5 a, c$ and $6 a, c$ shows the variation of the friction coefficient with sliding velocity within the normal load range studied for nanoclay-based ecolubricants made up of an oil mixture with a viscosity of $140.5 \mathrm{cSt}$ and nanoclay concentrations of $0.5,3.3$, and $6.0 \mathrm{wt}$. $\%$. Figures 5 and 6 refer to the Pangel B20 and Cloisite-based ecolubricants, respectively. At 10 $\mathrm{N}$, all these dispersions showed values of the friction coefficient on the boundary friction regime around 0.13 for Pangel B20, and 0.11 for Cloisite 15A, regardless of the nanoclay concentration. When the fluid friction became increasingly important, i.e., along the mixed/EHD lubrication regime, lower nanoclay concentrations yielded a more significant reduction in the friction coefficient values as the sliding velocity was increased, despite its lower high shear rate-limiting viscosity. Therefore, a concentration as low as $0.5 \mathrm{wt} \%$ of these nanoclays resulted in improved mixed and fluid friction at $10 \mathrm{~N}$, comparable to the neat vegetable oils. On the other hand, the application of $40 \mathrm{~N}$ led to significant worsening of the friction behavior along the mixed/EHD lubrication regime, becoming more important with decreasing nanoclay concentration, i.e., for nanoclay concentrations equal to and lower than $3.3 \mathrm{wt}$.\%. It is worth pointing out that a higher concentration was able to successfully withstand the highest normal load applied, within the entire sliding 
velocity range studied. In this sense, the highest concentration used of these nanoclays, $6.0 \mathrm{wt} . \%$, mitigated the adverse effect provoked by the application of the highest normal load on the friction coefficient, thus yielding more similar friction curves at 10 and $40 \mathrm{~N}$, and the lowest friction coefficient in the boundary friction region. Thus, Pangel B20 provoked a reduction of $25 \%$ of the friction coefficient at the boundary region. We therefore conclude that these nanoclays, at $6.0 \mathrm{wt} . \%$, may act as friction improvers at high normal load and might prevent the mating surfaces from excessive contact between asperities, thereby reducing wear $[25,27,41]$, as it is shown below.

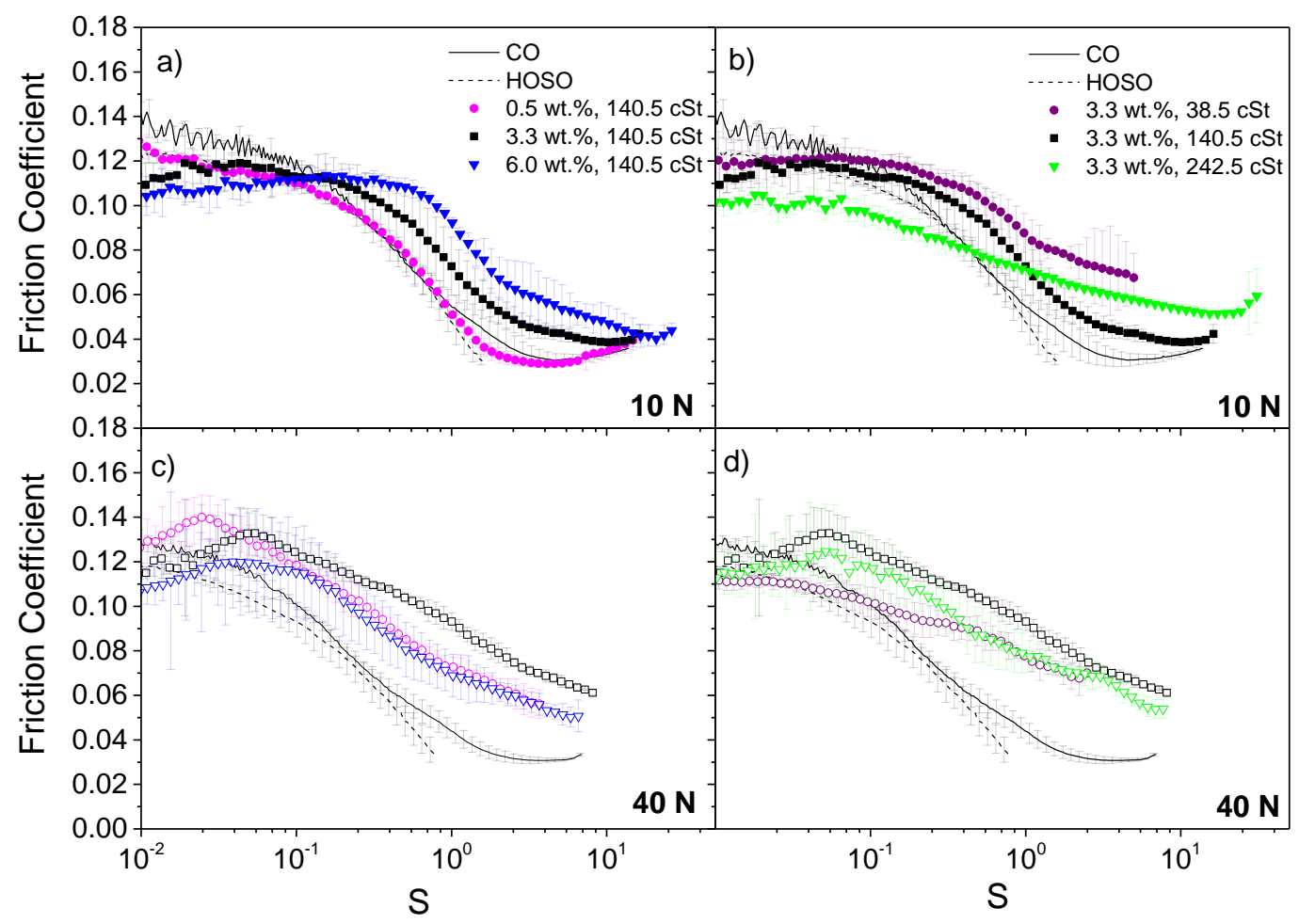

Figure 6. Evolution of the friction coefficient with the sliding velocity for Cloisite $15 \mathrm{~A}$-based dispersions at $25^{\circ} \mathrm{C}$ as a function of nanoclay concentration (a,c) and oil viscosity (b,d), at $10 \mathrm{~N}((\mathbf{a}, \mathbf{b})$ solid symbols) and $40 \mathrm{~N}((\mathbf{c}, \mathbf{d})$ empty symbols). Both neat vegetable oils curves were introduced as reference.

Different mechanisms have been proposed in the literature in order to describe the acting of these nanoclays on the friction process. Regarding the Cloisite 15A, due to their weakly bound layered structure, the nanoclay platelets will easily shear and enhance the frictional response once in contact [25]. In this sense, lower friction coefficients were obtained with Cloisite 15A under mixed and fluid friction conditions. In addition, the interacting forces between layers can be broken under both the high load and the friction heat, which is known as exfoliation [24]. This action releases numerous smaller particles that can be adsorbed onto the metal surface, reducing its effective roughness but increasing the real contact area [41,42]. Consequently, much higher friction coefficients were observed for Cloisite 15A at $40 \mathrm{~N}$ than at $10 \mathrm{~N}$. In contrast, the sepiolite Pangel B20 may act like other fiber-like nanoparticles, yielding a more viscous lubricant film as discussed above, and thus create a protecting tribofilm that effectively lowers metal-metal contact. In addition, they may provide a "rolling bearing" effect due to their tubular shape [43,44]. In general, it is worth emphasizing the good load-carrying capability demonstrated by these $6.0 \mathrm{wt} . \%$ nanoclay-based ecolubricants.

With respect to oil viscosity effect, Figures $5 b$,d and $6 b$,d show the variation of the friction coefficient with sliding velocity, within the normal load range studied, for nanoclaybased ecolubricants with $3.3 \mathrm{wt}$.\% of nanoclay and oil viscosities of 38.5, 140.5, and 242.5 cSt. At $10 \mathrm{~N}$, the $3.3 \mathrm{wt} . \%$ dispersions showed an improvement in the friction behavior 
along the mixed/EHD lubrication regime for oil viscosities equal to and higher than 140.5 $\mathrm{Pa} \cdot \mathrm{s}$. As expected, a higher oil viscosity enabled a thicker tribofilm, which contributed to separate the mating surfaces and to reduce the contact between asperities. This effect was drastically reduced at $40 \mathrm{~N}$, for which no significant differences in the friction coefficient were found within the oil viscosity range studied.

\subsection{Wear Analysis of Nanoclays-Based Ecolubricants}

The wear scar analysis was performed under stationary friction tests, with a duration of $1800 \mathrm{~s}$, within the mixed lubrication region $(40 \mathrm{~N}, 16 \mathrm{~mm} / \mathrm{s})$. Mixed lubrication is known to be strongly influenced by the base oil and additive used, and also by the characteristics of the metal surface [45]. Therefore, the anti-wear properties of these nanoclays were examined as a combined effect of both nanoclay concentration and oil viscosity (following the above explained experimental design). For the sake of comparison, both wear scar diameter and friction coefficient of the two neat vegetable oils used were displayed in Figure 7. Wear scar diameters of $520.1 \pm 13 \mu \mathrm{m}$ and $689 \pm 29 \mu \mathrm{m}$ were found for $\mathrm{CO}$ and HOSO, respectively.

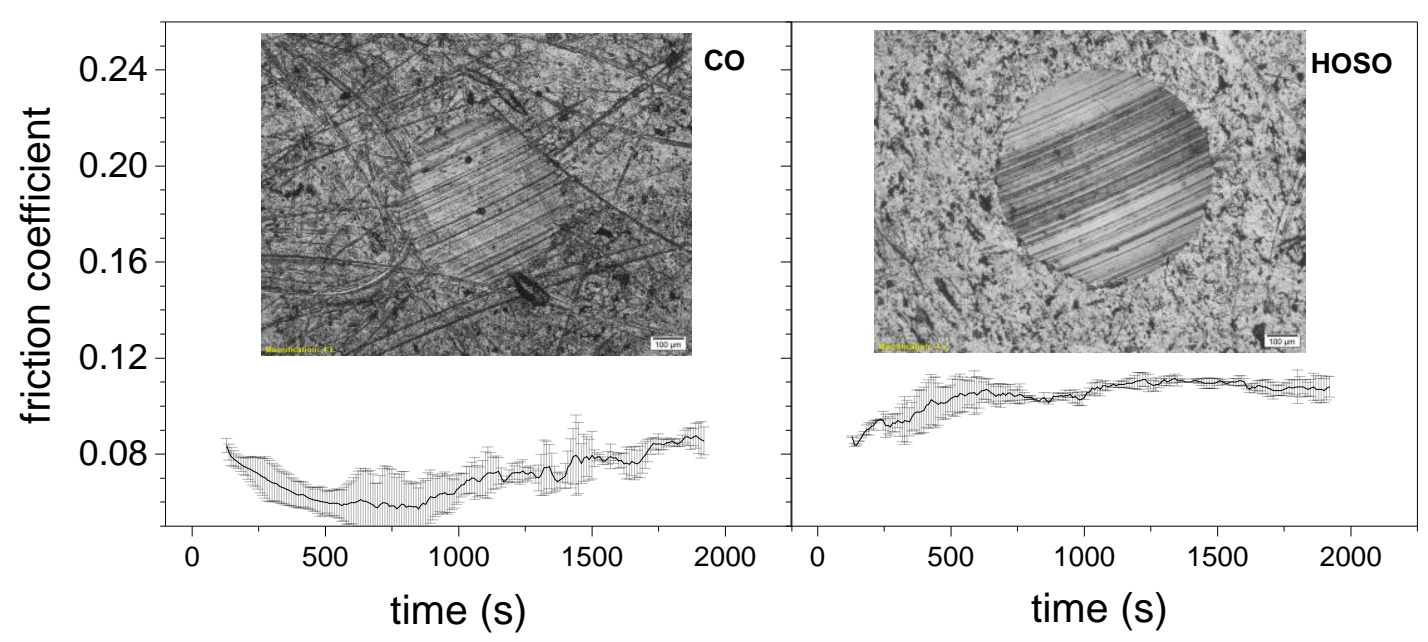

Figure 7. Wear scars and variation of friction coefficient during wear tests at constant sliding velocity of $16 \mathrm{~mm} / \mathrm{s}$ and normal load of $40 \mathrm{~N}$ for castor and high oleic sunflowers oils. Friction coefficient dispersion along the test is displayed with the error bars.

Figures 8 and 9 show the variation of the friction coefficient and the wear scar obtained upon completion of the wear test. In general, the optical micrographs of wear scars on the steel plates revealed differences in the extent of wear, i.e., scar diameters, depending on both nanoclay concentration and oil viscosity. Moreover, the morphology of the mating surfaces suggested that the predominant wear mechanism was abrasion on the metal surface, with high-density furrows in the whole width of the diameter, in accordance with the existing literature $[25,27,41]$. In relation with friction behavior, in general, the friction coefficient at the very early stage of each experiment performed was seen to increase for the dispersions with the lowest oil viscosity but decreased for the others. Although the friction coefficients reached steady-state values in most of the cases, some nanoclay-based ecolubriants showed a monotonic increase in the friction coefficient with the time. In addition, the friction coefficients of $0.5 \mathrm{wt} . \%$ Pangel B20-based dispersions showed undesirable fluctuations along the test, probably due to failure in the stability or load-carrying capability of the lubricating film. In this sense, the largest wear scar diameters were appreciated for the nanoclay-based ecolubricants with the lowest concentration studied, $0.5 \mathrm{wt} . \%$, for which wear scar diameters of $1024 \pm 57 \mu \mathrm{m}$ and $893 \pm 51 \mu \mathrm{m}$ were found for Cloisite 15A and Pangel B20, respectively (Figures 8 and 9 and Table 2). Both samples showed higher wear scar diameters than the neat vegetable oils studied. 
Table 2. Wear scar diameters obtained from wear tests at constant sliding velocity of $16 \mathrm{~mm} / \mathrm{s}$ and normal load of $40 \mathrm{~N}$ for all nanoclay-based dispersions studied.

\begin{tabular}{ccccc}
\hline Sample & $\begin{array}{c}\text { Nanoclay } \\
\text { Concentration (wt.\%) }\end{array}$ & $\begin{array}{c}\text { Oil Viscosity } \\
(\mathbf{c S t})\end{array}$ & $\begin{array}{c}\text { Cloisite 15A } \\
\mathbf{D}(\boldsymbol{\mu m})\end{array}$ & $\begin{array}{c}\text { Pangel B20 } \\
\mathbf{D}(\boldsymbol{\mu m})\end{array}$ \\
\hline $0,0 \mathrm{~A}$ & 3.3 & 140.5 & $790 \pm 60$ & $505 \pm 25$ \\
$0,0 \mathrm{~B}$ & 3.3 & 140.5 & $857 \pm 28$ & $669 \pm 26$ \\
$+1.414,0$ & 6.0 & 140.5 & $642 \pm 37$ & $285 \pm 10$ \\
$-1.414,0$ & 0.5 & 140.5 & $1024 \pm 57$ & $893 \pm 51$ \\
$0,+1.414$ & 3.3 & 242.5 & $347 \pm 55$ & $315 \pm 19$ \\
$0,-1.414$ & 3.3 & 38.5 & $839 \pm 43$ & $378 \pm 18$ \\
$+1,+1$ & 5.2 & 212.6 & $953 \pm 66$ & $338 \pm 50$ \\
$+1,-1$ & 5.2 & 68.4 & $893 \pm 72$ & $298 \pm 10$ \\
$-1,+1$ & 1.3 & 212.6 & $747 \pm 64$ & $607 \pm 66$ \\
$-1,-1$ & 1.3 & 68.4 & $848 \pm 86$ & $445 \pm 19$ \\
\hline
\end{tabular}

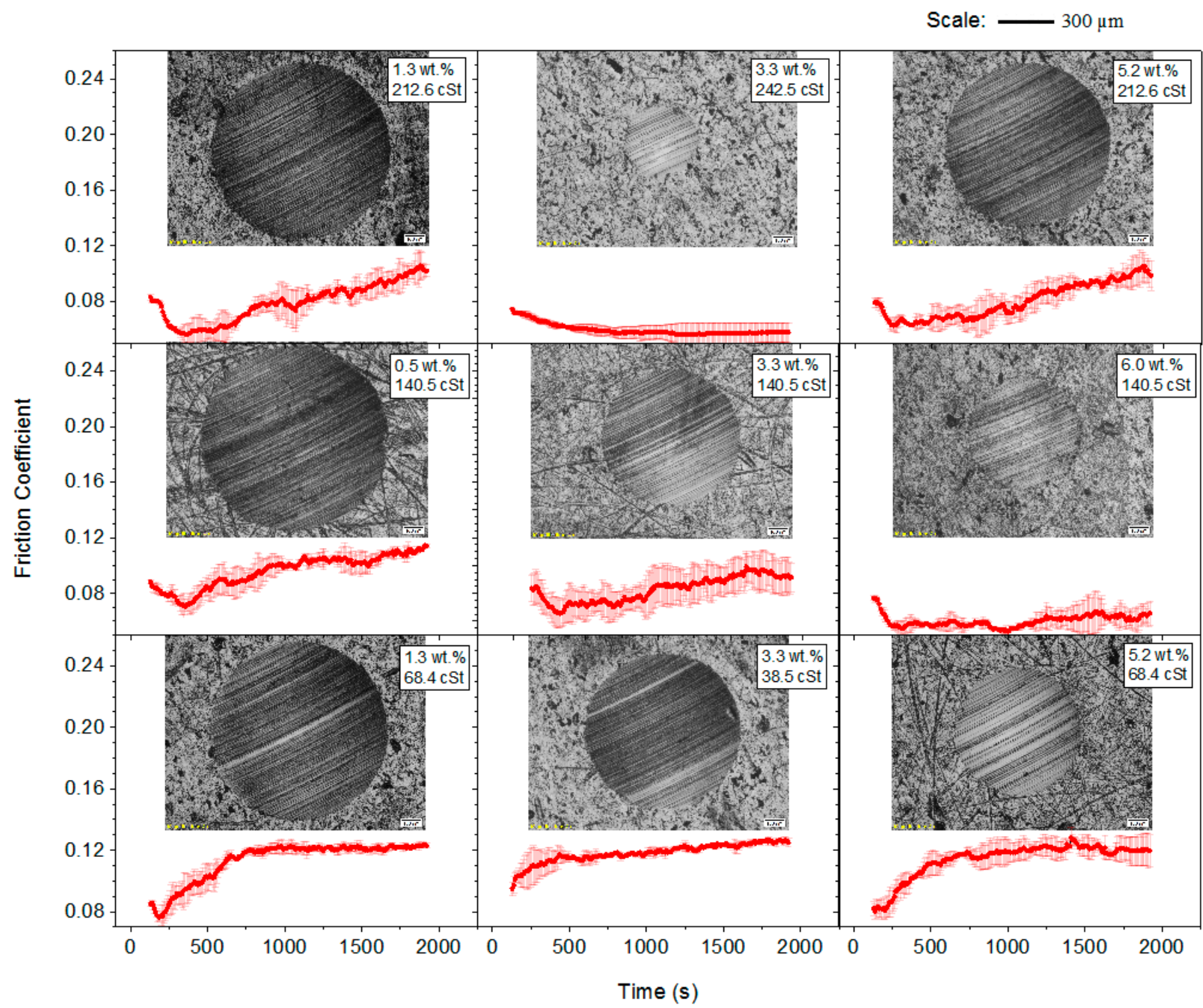

Figure 8. Wear scars and variation of friction coefficient during wear tests at constant sliding velocity of $16 \mathrm{~mm} / \mathrm{s}$ and normal load of $40 \mathrm{~N}$ for Cloisite 15A. Friction coefficient dispersion along the tests are displayed with the error bars. 


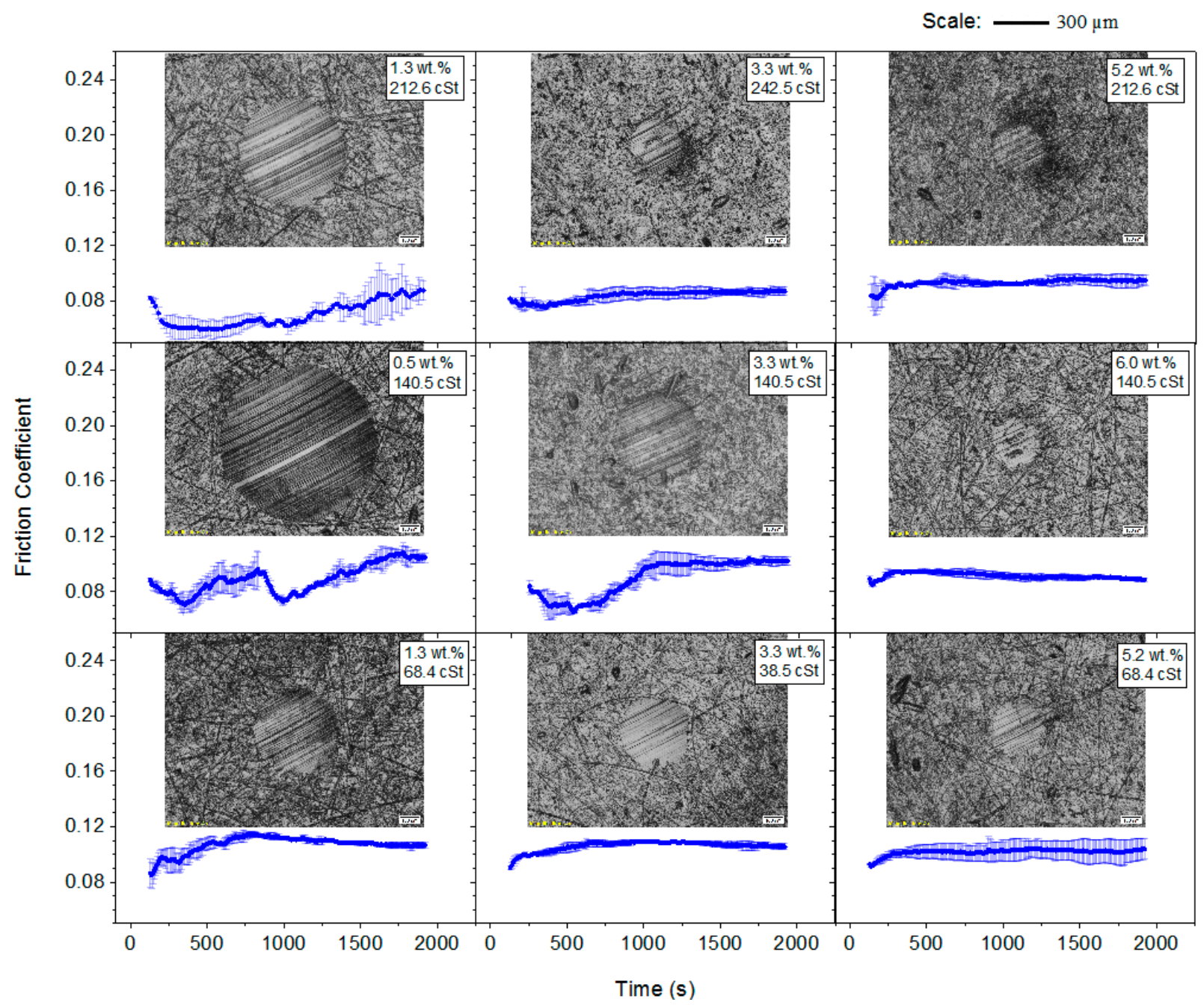

Figure 9. Wear scars and variation of friction coefficient during wear tests at constant sliding velocity of $16 \mathrm{~mm} / \mathrm{s}$ and normal load of $40 \mathrm{~N}$ for Pangel B20. Friction coefficient dispersion along the tests is displayed with the error bars.

As expected from the previous Stribeck-like curves discussed above (Figures 5 and 6 ), the friction coefficients were significantly reduced at $40 \mathrm{~N}$ by the effect of the oil viscosity and nanoclay concentration within the mixed lubrication region. As can be appreciated in Figure 8 , an increase in the Cloisite 15A concentration brought about a reduction in the friction coefficient at a comparable oil viscosity of $140.5 \mathrm{cSt}$ (middle row). The combination of $6.0 \mathrm{wt} . \%$ Cloisite 15A with an oil viscosity of $140.5 \mathrm{cSt}$ allowed achievement of an important reduction in the friction coefficient in the same order as $3.3 \mathrm{wt} . \%$ with an oil viscosity of $242.5 \mathrm{cSt}$. Thus, wear scar diameters of $642 \pm 37$ and $347 \pm 55 \mu \mathrm{m}$ were obtained, respectively. The last showed a reduction up to $66 \%$ relative to the one obtained with castor oil. It is worth pointing out that the dispersion with $3.3 \mathrm{wt} . \%$ and $242.5 \mathrm{cSt}(0,+1.414)$ enabled a smoother evolution of the friction coefficient with time and the lowest amongst the wear scar diameters measured. However, the combination of a higher concentration of $5.2 \mathrm{wt}$.\% with a similar oil viscosity of $212.6 \mathrm{cSt}$ yielded much larger values of wear scar diameter and friction coefficient than expected (Figure 8). Unfortunately, further study is still required before we can provide an explanation to this issue. These results seem to point out that the easy shearing of this layered montmorillonite (Cloisite 15A) may be the reason behind the enhanced frictional response and milder wear regime observed. Such a mechanism could be responsible for both the good load-carrying capability and the enhanced anti-wear performance of this Cloisite 15A-based ecolubricant. 
As for Pangel B20-based ecolubricants (Figure 9 and Table 2), significantly higher reductions of wear scar diameters with nanoclay concentration were observed, even with low oil viscosities. Even so, the reduction in the friction coefficient was not so evident (Figure 9). Thus, a significant decrease from $893 \pm 51$ down to $285 \pm 10 \mu \mathrm{m}$ was achieved when the concentration was increased from $0.5 \mathrm{up}$ to $6 \mathrm{wt} . \%$, whilst keeping the oil viscosity of $140.5 \mathrm{cSt}$ constant (Table 2). It is worth noting that the formulations, $6.0 \mathrm{wt} . \%, 140.5 \mathrm{cSt}$; $5.2 \mathrm{wt} . \%, 212.6 \mathrm{cSt}$; and $3.3 \mathrm{wt} . \%, 242.5 \mathrm{cSt}$, led to similar wear scar diameters of $285 \pm 10$, $338 \pm 50$, and $315 \pm 19 \mu \mathrm{m}$, respectively. They were much smaller than both neat vegetable oils, despite the larger friction coefficient in the Stribeck curve. However, these wear scars show distinctive abrasive grooves in the central area, which may indicate much more localized and tighter the contacts were during sliding. This local surface damage could be a consequence of agglomeration of nanofibers during the friction process, causing slightly higher friction coefficient as compared to the layered montmorillonite (Cloisite 15A). Even so, the use of the fiber-like sepiolite (Pangel B20) reduced the wear scar diameters significantly, due to a better tribofilm forming capacity and its "rolling bearing" effect.

\section{Conclusions}

The dispersions studied, only based on nanoclay and vegetable oil, have shown interesting rheological and tribological behavior such as viscosity improving, friction reducing, load-carrying, and anti-wear properties.

With respect to their rheological behavior, Pangel B20-based dispersions showed higher values of dynamic viscosity than Cloisite 15A within the whole shear rate range studied. In fact, the physical entanglements among fibers in Pangel B20-based ecolubricants involved values of consistency index up to 25 times higher than those with Cloisite 15A. Moreover, all dispersions prepared with this natural fiber-like sepiolite (Pangel B20) showed a pseudoplastic behavior, which was well-fitted by the Sisko model. For layered montmorillonite (Cloisite 15A) based ecolubricants, the shear rate had no effect on the viscosity when the concentration was equal to or lower than $1.3 \mathrm{wt} . \%$. It is noteworthy that the pseudoplastic behavior depended mainly on the nanoclay concentration and only slightly on the oil viscosity for Cloisite 15A-based dispersions. In addition, the strong physical entanglements within the Pangel B20 network involved lower flow index values and, consequently, higher flow behavior dependence on concentration.

In relation with their tribological properties, a significant reduction in the friction coefficient along the mixed/EHD lubrication regime was obtained for nanoclay concentrations lower than $3.3 \mathrm{wt} . \%$ at $10 \mathrm{~N}$. At $40 \mathrm{~N}$, Pangel B20-based ecolubricants showed promising results at the highest concentration studied, $6.0 \mathrm{wt} . \%$, with a significant reduction in the friction coefficient within the boundary lubrication regime. Moreover, lower wear scar diameters were attained with Pangel B20-based dispersions at concentrations higher than $3.3 \mathrm{wt} . \%$, regardless of oil viscosity used. In contrast, only the combination of $3.3 \mathrm{wt} . \%$ Cloisite 15A with an oil viscosity of $242.5 \mathrm{cSt}$ yielded a comparable small diameter, although with a more uniform wear scar. Even though both nanoclays possess good load-carrying capability and anti-wear properties, the fiber-like sepiolite (Pangel B20) revealed better potential.

Author Contributions: Conceptualization, M.A.D. and M.G.-M.; methodology, M.A.D. and C.R.; software, S.D.F.-S.; validation, C.R. and S.D.F.-S.; formal analysis, S.D.F.-S.; investigation, C.R. and S.D.F.-S.; resources, C.R.; data curation, C.R. and S.D.F.-S.; writing-original draft preparation, M.A.D. and S.D.F.-S.; writing - review and editing, M.G.-M.; visualization, M.A.D. and M.G.-M.; supervision, M.A.D.; project administration, M.A.D. and M.G.-M.; funding acquisition, M.A.D. and M.G.-M. All authors have read and agreed to the published version of the manuscript.

Funding: Programa Operativo FEDER-Andalucía 2014-2020 (UHU-1255843) and the Consejería de Economía y Conocimiento de la Junta de Andalucía: UHU-1255843.

Informed Consent Statement: Not applicable.

Data Availability Statement: Not applicable. 
Acknowledgments: This work is part of a Research Project sponsored by "Programa Operativo FEDERAndalucía 2014-2020" (UHU-1255843) and the "Consejería de Economía y Conocimiento de la Junta de Andalucía". The authors gratefully acknowledge the financial support. S. Fernández-Silva also acknowledges the program "Ayudas para la promoción de empleo joven e implantación de la Garantía Juvenil en I+D+i en el Subprograma Estatal de Incorporación, del Programa Estatal de Promoción del Talento y su Empleabilidad en I+D+i" (PEJ2018-003949-A) for funding his research contract.

Conflicts of Interest: The authors declare no potential conflicts of interest with respect to the research, authorship, and/or publication of this article.

\section{References}

1. Chan, C.H.; Tang, S.W.; Mohd, N.K.; Lim, W.H.; Yeong, S.K.; Idris, Z. Tribological behavior of biolubricant base stocks and additives. Renew. Sustain. Energy Rev. 2018, 93, 145-157. [CrossRef]

2. Singh, Y.; Sharma, A.; Singla, A. Non-edible vegetable oil-based feedstocks capable of bio-lubricant production for automotive sector applications-A review. Environ. Sci. Pollut. Res. 2019, 26, 14867-14882. [CrossRef] [PubMed]

3. Darminesh, S.P.; Sidik, N.A.C.; Najafi, G.; Mamat, R.; Ken, T.L.; Asako, Y. Recent development on biodegradable nanolubricant: A review. Int. Commun. Heat Mass Transf. 2017, 86, 159-165. [CrossRef]

4. Rudnick, L.R. Synthetics, Mineral Oils, and Bio-Based Lubricants: Chemistry and Technology, 3rd ed.; CRC Press: Boca Raton, FL, USA, 2005; ISBN 9781420027181.

5. Erhan, S.Z.; Asadauskas, S. Lubricant basestocks from vegetable oils. Ind. Crops Prod. 2000, 11, 277-282. [CrossRef]

6. Ogunniyi, D.S. Castor oil: A vital industrial raw material. Bioresour. Technol. 2006, 97, 1086-1091. [CrossRef]

7. Quinchia, L.A.; Delgado, M.A.; Valencia, C.; Franco, J.M.; Gallegos, C. Viscosity modification of different vegetable oils with EVA copolymer for lubricant applications. Ind. Crops Prod. 2010, 32, 607-612. [CrossRef]

8. Quinchia, L.A.; Delgado, M.A.; Valencia, C.; Franco, J.M.; Gallegos, C. Natural and synthetic antioxidant additives for improving the performance of new biolubricant formulations. J. Agric. Food Chem. 2011, 59, 12917-12924. [CrossRef]

9. Lee, K.; Hwang, Y.; Cheong, S.; Choi, Y.; Kwon, L.; Lee, J.; Kim, S.H. Understanding the role of nanoparticles in nano-oil lubrication. Tribol. Lett. 2009, 35, 127-131. [CrossRef]

10. Ghaednia, H.; Jackson, R.L. Fellowship research: The role of nanoparticles in lubricants; Performing lubricated and dry friction tests. Tribol. Lubr. Technol. 2015, 71, 20-24.

11. Chen, Y.; Renner, P.; Liang, H. Dispersion of nanoparticles in lubricating oil: A critical review. Lubricants 2019, 7, 7. [CrossRef]

12. Tarasov, S.; Kolubaev, A.; Belyaev, S.; Lerner, M.; Tepper, F. Study of friction reduction by nanocopper additives to motor oil. Wear 2002, 252, 63-69. [CrossRef]

13. Padgurskas, J.; Rukuiza, R.; Prosyčevas, I.; Kreivaitis, R. Tribological properties of lubricant additives of Fe, Cu and Co nanoparticles. Tribol. Int. 2013, 60, 224-232. [CrossRef]

14. Hernandez Battez, A.; Fernandez Rico, J.E.; Navas Arias, A.; Viesca Rodriguez, J.L.; Chou Rodriguez, R.; Diaz Fernandez, J.M. The tribological behaviour of $\mathrm{ZnO}$ nanoparticles as an additive to PAO6. Wear 2006, 261, 256-263. [CrossRef]

15. Hernández Battez, A.; González, R.; Viesca, J.L.; Fernández, J.E.; Díaz Fernández, J.M.; Machado, A.; Chou, R.; Riba, J. CuO, ZrO2 and $\mathrm{ZnO}$ nanoparticles as antiwear additive in oil lubricants. Wear 2008, 265, 422-428. [CrossRef]

16. Luo, T.; Wei, X.; Huang, X.; Huang, L.; Yang, F. Tribological properties of Al2O3 nanoparticles as lubricating oil additives. Ceram. Int. 2014, 40, 7143-7149. [CrossRef]

17. Shahnazar, S.; Bagheri, S.; Abd Hamid, S.B. Enhancing lubricant properties by nanoparticle additives. Int. J. Hydrogen Energy 2016, 41, 3153-3170. [CrossRef]

18. Jiao, D.; Zheng, S.; Wang, Y.; Guan, R.; Cao, B. The tribology properties of alumina/silica composite nanoparticles as lubricant additives. Appl. Surf. Sci. 2011, 257, 5720-5725. [CrossRef]

19. Gupta, R.N.; Harsha, A.P. Antiwear and extreme pressure performance of castor oil with nano-additives. Proc. Inst. Mech. Eng. Part J J. Eng. Tribol. 2018, 232, 1055-1067. [CrossRef]

20. Gupta, R.N.; Harsha, A.P. Tribological evaluation of calcium-copper-titanate/cerium oxide-based nanolubricants in sliding contact. Lubr. Sci. 2018, 30, 175-187. [CrossRef]

21. Li, Z.; Xu, C.; Xiao, G.; Zhang, J.; Chen, Z.; Yi, M. Lubrication performance of graphene as lubricant additive in 4-n-pentyl-4' cyanobiphyl Liquid Crystal (5CB) for Steel/Steel contacts. Materials 2018, 11, 2110. [CrossRef]

22. Zhao, J.; Li, Y.; He, Y.; Luo, J. In Situ Green Synthesis of the New Sandwichlike Nanostructure of Mn3O4/Graphene as Lubricant Additives. ACS Appl. Mater. Interfaces 2019, 11, 36931-36938. [CrossRef] [PubMed]

23. Del Ramos-Tejada, M.M.; Rodríguez, J.M.; Delgado, Á.V. Electrorheology of clay particle suspensions. Effects of shape and surface treatment. Rheol. Acta 2018, 57, 405-413. [CrossRef]

24. Chizhik, P.; Dietzel, D.; Bill, S.; Schirmeisen, A. Tribological properties of a phyllosilicate based microparticle oil additive. Wear 2019, 426-427, 835-844. [CrossRef]

25. Singh, H.; Bhowmick, H. Influence of nanoclay on the thermophysical properties and lubricity characteristics of mineral oil. In Materials Today, Proceedings of the International Conference on Nanotechnology: Ideas, Innovations \& Initiatives-2017 (ICN:3i-2017), Roorkee, India, 6-8 December 2017; Elsevier BV: Amsterdam, The Netherlands, 2019; Volume 18, pp. $1058-1066$. 
26. García-López, D.; Fernández, J.F.; Merino, J.C.; Santarén, J.; Pastor, J.M. Effect of organic modification of sepiolite for PA 6 polymer/organoclay nanocomposites. Compos. Sci. Technol. 2010, 70, 1429-1436. [CrossRef]

27. Cao, Z.; Xia, Y.; Xi, X. Nano-montmorillonite-doped lubricating grease exhibiting excellent insulating and tribological properties. Friction 2017, 5, 219-230. [CrossRef]

28. Zhuang, G.; Zhang, Z.; Yang, H.; Tan, J. Structures and rheological properties of organo-sepiolite in oil-based drilling fluids. Appl. Clay Sci. 2018, 154, 43-51. [CrossRef]

29. Liu, P.; Du, M.; Clode, P.; Li, H.; Liu, J.; Leong, Y.K. Surface Chemisty, Microstructure, and Rheology of Thixotropic 1-D Sepiolite Gels. Clays Clay Miner. 2020, 68, 9-22. [CrossRef]

30. Montgomery, D. Diseño Y Análisis De Experimentos; Limusa Wiley: Mexico City, Mexico, 2004; ISBN 9687270608.

31. Maheswaran, R.; Sunil, J. Effect of nano sized garnet particles dispersion on the viscous behavior of extreme pressure lubricant oil. J. Mol. Liq. 2016, 223, 643-651. [CrossRef]

32. Heyer, P.; Läuger, J. Correlation between friction and flow of lubricating greases in a new tribometer device. Lubr. Sci. 2009, 21, 253-268. [CrossRef]

33. Martín-Alfonso, J.E.; Martín-Alfonso, M.J.; Franco, J.M. Tunable rheological-tribological performance of "green" gel-like dispersions based on sepiolite and castor oil for lubricant applications. Appl. Clay Sci. 2020, 192. [CrossRef]

34. Kuznetsov, N.M.; Stolyarova, D.Y.; Belousov, S.I.; Kamyshinsky, R.A.; Orekhov, A.S.; Vasiliev, A.L.; Chvalun, S.N. Halloysite nanotubes: Prospects in electrorheology. Express Polym. Lett. 2018, 12, 958-965. [CrossRef]

35. Balan, C.; Franco, J.M. Influence of the geometry on the transient and steady flow of lubricating greases. Tribol. Trans. 2001, 44, 53-58. [CrossRef]

36. Hou, K.; Ouyang, J.; Zheng, C.; Zhang, J.; Yang, H. Surface-modified sepiolite fibers for reinforcing resin brake composites. Mater. Express 2017, 7, 104-112. [CrossRef]

37. Papenhuijzen, J.M.P. The role of particle interactions in the rheology of dispersed systems. Rheol. Acta 1972, 11, 73-88. [CrossRef]

38. Delgado, M.A.; Valencia, C.; Sánchez, M.C.; Franco, J.M.; Gallegos, C. Influence of soap concentration and oil viscosity on the rheology and microstructure of lubricating greases. Ind. Eng. Chem. Res. 2006, 45, 1902-1910. [CrossRef]

39. Delgado, M.A.; Franco, J.M.; Valencia, C.; Kuhn, E.; Gallegos, C. Transient shear flow of model lithium lubricating greases. Mech. Time-Depend. Mater. 2009, 13, 63-80. [CrossRef]

40. Gonçalves, D.; Graça, B.; Campos, A.V.; Seabra, J. On the friction behaviour of polymer greases. Tribol. Int. 2016, 93, 399-410. [CrossRef]

41. Yu, H.L.; Xu, Y.; Shi, P.J.; Wang, H.M.; Zhao, Y.; Xu, B.S.; Bai, Z.M. Tribological behaviors of surface-coated serpentine ultrafine powders as lubricant additive. Tribol. Int. 2010, 43, 667-675. [CrossRef]

42. García-Morales, M.; Fernández-Silva, S.D.; Roman, C.; Delgado, M.A. Electro-active control of the viscous flow and tribological performance of ecolubricants based on phyllosilicate clay minerals and castor oil. Appl. Clay Sci. 2020, 198, 1058302. [CrossRef]

43. Peña-Parás, L.; Maldonado-Cortés, D.; García, P.; Irigoyen, M.; Taha-Tijerina, J.; Guerra, J. Tribological performance of halloysite clay nanotubes as green lubricant additives. Wear 2017, 376-377, 885-892. [CrossRef]

44. Kalin, M.; Kogovšek, J.; Remškar, M. Mechanisms and improvements in the friction and wear behavior using MoS 2 nanotubes as potential oil additives. Wear 2012, 280-281, 36-45. [CrossRef]

45. Gunsel, S.; Smeeth, M.; Spikes, H. Friction and wear reduction by boundary film-forming viscosity index improvers. $S A E$ Tech Pap. Ser. 1996. [CrossRef] 